\title{
Article \\ Genetic Differentiation in Anthocyanin Content among Berry Fruits
}

\author{
Alicja Ponder (D), Ewelina Hallmann*D, Martyna Kwolek, Dominika Średnicka-Tober (D) \\ and Renata Kazimierczak (D)
}

Citation: Ponder, A.; Hallmann, E.; Kwolek, M.; Średnicka-Tober, D.;

Kazimierczak, R. Genetic

Differentiation in Anthocyanin Content among Berry Fruits.

Curr. Issues Mol. Biol. 2021, 43, 36-51. https://doi.org/10.3390/

cimb43010004

Academic Editor: Hany A. El-Shemy

Received: 30 March 2021

Accepted: 27 April 2021

Published: 29 April 2021

Publisher's Note: MDPI stays neutral with regard to jurisdictional claims in published maps and institutional affiliations.

Copyright: (c) 2021 by the authors. Licensee MDPI, Basel, Switzerland. This article is an open access article distributed under the terms and conditions of the Creative Commons Attribution (CC BY) license (https:// creativecommons.org/licenses/by/ $4.0 /)$.
Department of Functional and Organic Food, Institute of Human Nutrition Sciences, Warsaw University of Life Sciences, Nowoursynowska 159c, 02-776 Warsaw, Poland; alicja_ponder1@sggw.edu.pl (A.P.); martyna.d.kwolek@gmail.com (M.K.); dominika_srednicka_tober@sggw.edu.pl (D.Ś.-T.); renata_kazimierczak@sggw.edu.pl (R.K.)

* Correspondence: ewelina_hallmann@sggw.edu.pl; Tel.: +48-22-59-37-036

\begin{abstract}
Anthocyanins are widely distributed secondary metabolites that play an essential role in skin pigmentation of many plant organs and microorganisms. Anthocyanins have been associated with a wide range of biological and pharmacological properties. They are also effective agents in the prevention and treatment of many chronic diseases. Berries are particularly abundant in these compounds; therefore, their dietary intake has health-promoting effects. The aim of this study was to identify and determine the anthocyanin content in selected species and cultivars of berry fruits, such as raspberry, blackberry, red currant, blackcurrant, and highbush blueberry, widely consumed by Europeans. The concentrations of anthocyanins were determined by HPLC, identifying individual compounds: cyanidin-3-O-glucoside, pelargonidin-3-O-glucoside, delphinidin3-O-glucoside, delphinidin-3-O-rutinoside, cyanidin-3-O-rutinoside, delphinidin-3-O-galactoside, cyanidin-3-O-galactoside, and malvidin-3-O-galactoside. The experimental data showed that the selected species and cultivars of berry fruits differ significantly in the contents of anthocyanins. Among all species tested, blackberry and blackcurrant were characterized significantly by the highest content of anthocyanins (sum), while the lowest content was found in red currant fruits. Additionally, the content of individual anthocyanin compounds in particular species and cultivars was also different. Considering the high content of anthocyanins and their potential positive impact on human health and protection against disease, berries should be part of healthy nutrition.
\end{abstract}

Keywords: anthocyanin; bioactive compounds; HPLC method; berry fruits; raspberry; blackberry; red currant; blackcurrant; highbush blueberry

\section{Introduction}

Anthocyanins are widely distributed secondary metabolites that play an essential role in skin pigmentation of many plant organs and microorganisms [1]. They are flavonoids by classification, sharing the same diphenylpropane skeleton $\left(\mathrm{C}_{6} \mathrm{C}_{3} \mathrm{C}_{6}\right)$ (Figure 1), and are predominantly found in berry fruits [2]. Actually, 25 different anthocyanidins are known, which differ from each other in the presence of hydroxyl $(-\mathrm{OH})$ and methoxy $(-\mathrm{OCH} 3)$ groups bound at the scaffold core [3]. These compounds have an important function for the quality control of foods that claim to contain specific anthocyanin-enriched fruits. The characteristic anthocyanin pattern is specific for each fruit. Based on this fingerprinting, it is possible to recognize the adulteration and/or sophistication of particular products that claim to contain a certain fruit. This method allows for the detection of a misidentification of the initial plant raw material or adulteration with other plants [3-6].

Anthocyanins are water soluble, and their spectral properties are usually responsible for the red, blue, and purple coloring of different plant parts (flowers, fruits, and other plant tissues). This is due to the accumulation of anthocyanins in the flesh and skin of the fruit $[7,8]$. In the case of fruits like peaches, apricots, plums, and grape berries, anthocyanins 
accumulate more in the skin than in the flesh [1]. Their specific color depends on the environmental $\mathrm{pH}$ and the presence, at the same time, of other compounds from flavone and flavonol groups and metal ions [9]. Depending on the $\mathrm{pH}$ value, anthocyanins can exist in many different protonated, deprotonated, hydrated, and isomeric forms. Due to changes in protonation and hydration at acidic $\mathrm{pH}(\mathrm{pH} 1-3)$, anthocyanins are red; at $\mathrm{pH} 4-5$, they are colorless or yellow; and at $\mathrm{pH}$ values between 6 and 7, they became blue-purple [10-12]. The role of anthocyanins in plants is in attracting plant pollinators and increasing stress tolerance. Floral color and scent are the traits that attract pollinators. Anthocyanins provide flowers with radiance and attractiveness, which can act as a beneficial visualization signal to pollinators, increasing the number of pollinator visits and thereby increasing the pollinator foraging efficiency and reproductive success. Additionally, apart from the floral parts, anthocyanins often occur transiently in the root, stem, fruits, and leaf tissues of plants at specific developmental stages in response to unfavorable environmental factors, including UV radiation, cold temperatures, and water stress. They play an important role in the natural protective mechanism of plants $[3,13]$.<smiles>CC1CCc2ccccc2O1</smiles>

Figure 1. Diphenylpropane skeleton $\left(\mathrm{C}_{6} \mathrm{C}_{3} \mathrm{C}_{6}\right)$ of all flavonoids.

Moreover, fruits, especially berries, are particularly abundant in different bioactive compounds, in that anthocyanins. The beneficial effects of these compounds for human health have been known from at least the 16th century [10]. There are a great number of studies devoted to the different biological effects exerted by anthocyanins. Anthocyanins have been associated with a wide range of biological and pharmacological properties. They are also effective in the prevention and treatment of many chronic diseases [11-14]. They exhibit antioxidant activity and inactivating properties against free radicals; moreover, anthocyanins can provide anti-inflammatory, antiviral, and anticancer effects [14]. The anticancer activity of anthocyanins contained in food results from their properties consisting of binding of mutagens, inhibiting metabolic activation of pro-mutagens, removing free radicals, inhibiting cancer cell proliferation, intensifying DNA repair processes, and inducing apoptosis of cancer cells. They can also influence cell differentiation, exhibit cytotoxic and cytostatic effects against cancer, and regulate the immune system [14].

Nevertheless, anthocyanins are also used in the development of food colorants and functional ingredients in food. However, the use of anthocyanins as food colorants and functional foods ingredients is limited because of the low stability of anthocyanins under the environmental conditions (heat, oxygen, and light among others) experienced during processing and storage $[11,15,16]$. The anthocyanin content depends on the balance between biosynthesis and degradation. Genetic, developmental, and environmental factors all regulate anthocyanin metabolism. The genetic differences found in raw materials appear to be highly relevant for the anthocyanin content [17]. This study will be helpful in designing strategies for obtaining anthocyanin-rich crops via species and variety control.

Anthocyanin compounds form noncovalent complexes with other flavonoids (copigments), such as flavones and flavonols, that can stabilize the color. This phenomenon is called co-pigmentation. The co-pigmentation complex is, however, more stable when the anthocyanin pigments are acylated, as the acylated pigments form more stable complexes when they are linked through the sugar residue by aromatic and/or aliphatic phenolic acyl moieties. Therefore, acylated anthocyanins have improved color stability in the $4-5 \mathrm{pH}$ 
range and retain the color in the mildly acidic $\mathrm{pH}$ environment of many food products as compared to nonacylated anthocyanins, which are nearly colorless at this $\mathrm{pH}$ range. Acylated anthocyanins can also withstand degradation at higher temperatures and at longer light exposures. As a result, foods added with acylated anthocyanin colorants have a longer shelf-life [18].

Berry-type fruits have long been regarded as having considerable health benefits because of their nutritional attributes, particularly their total antioxidant activity against cellular oxidation reactions. These discoveries have stimulated research to investigate the anthocyanins status of distinct berry fruit species and cultivars from different countries. There are a great variety of species from diverse botanical families (e.g., raspberry (Rubus ideus L.), blackberry (Rubus L.), red currant (Ribes L.), blackcurrant (Ribes nigrum L.), highbush blueberry (Vaccinium corymbosum L.) that produce the small purple or red fruits that are denoted as berries. In botanical terms, a berry is a fruit with many seeds and mesocarp flesh that evolves from a flower with a superior ovary [11,19]. Increased consumption of berry fruits, which are rich in nutrients and bioactive compounds like anthocyanins, can prevent various diseases and disorders. Bioactive compounds from berries have potent antioxidant, anticancer, antimutagenic, antimicrobial, anti-inflammatory, and antineurodegenerative properties [20-25]. Berry bioactive components impart anticancer effects through various complementary and overlapping mechanisms of action, including the induction of metabolizing enzymes, modulation of gene expression, and their effects on cell proliferation, apoptosis, and subcellular signaling pathways. Anthocyanins have received considerable interest in bearing possible relations to human health $[20,26-28]$. Along with fresh berries, a variety of berry products such as juice, wine, jam, and food colorants contribute significantly to the intake of anthocyanins. Additionally, there has been a growing trend in the use of berry extracts as ingredients in functional foods and dietary supplements [20].

Nowadays, a large number of scientific studies have established that dietary intake of berry fruits has a positive and profound effect on human health, performance, and disease protection, which are related to the high anthocyanin content of the berries. Therefore, in this paper, the identification and determination of the anthocyanin content in selected species and cultivars of berry fruit (raspberry (Rubus ideus L. Tulnameen cv.), blackberry (Rubus L. Darrow and Thornless Evergreen cv.), red currant (Ribes L. Detvan, Rovada, Heros, and Jonkheer van Tets cv.), blackcurrant (Ribes nigrum L. Ben Lomond and Titania cv.), and highbush blueberry (Vaccinium corymbosum L., Coville, Blue Gold, and Brigitta cv.)) were performed. Given the wide consumption of berry fruits and their potential positive impact on human health and disease protection, scientific research like this is important and useful. Moreover, it is equally important to disseminate this information to the general public in order to raise awareness of the beneficial effects of anthocyanin-rich products.

\section{Materials and Methods}

\subsection{Chemicals and Reagents}

The following chemicals and reagents were obtained: acetonitrile 99.9\% (HPLC grade, CAS no. 75-05-8), methanol (HPLC grade, CAS no. 67-56-1), acetic acid (glacial grade, CAS no. 64-19-7), and water (HPLC grade, CAS no. 7732-18-5). In addition, the following anthocyanin standards were obtained: cyanidin-3-O-glucoside (CAS no. 7084-24-4), pelargonidin-3-O-glucoside (CAS no. 18466-51-8), delphinidin-3-O-glucoside (CAS no. 690638-3), delphinidin-3-O-rutinoside (CAS no. 15674-58-5), cyanidin-3-O-rutinoside (CAS no. 18719-76-1), delphinidin-3-O-galactoside (CAS no. 27661-36-5), cya-nidin-3-O-galactoside, (CAS no. 27661-36-5), and malvidin-3-O-galactoside (CAS no. 643-84-5). All chemicals and reagents are produced by Sigma-Aldrich Chemical Company (Warsaw, Poland).

\subsection{Plant Material Origin}

Different species of berry fruits were collected directly from producers at the full maturity stage (characteristic for every species and cultivar). Farms were located in the 
Mazovia region in Poland. Experimental farms belonged to the organic farming system. According to law, the owners had qualified plant material as well a certificate validated by plant material producers on their farm. The mean amount of berry sample was $1 \mathrm{~kg}$ per cultivar. Fruit samples were transported to the laboratory and immediately separated into two parts; one part was used for dry matter determination and the other part for freeze-drying under the following conditions: temperature $-50{ }^{\circ} \mathrm{C}$, pressure $0.100 \mathrm{mBar}$, time $72 \mathrm{~h}$, and Freeze-drier LabconCo 2.5 equipment (Poland). After the drying process, fruits were milled with the A-80 laboratory mill.

\subsection{Dry Matter Determination}

The dry matter content was determined using the weight method. A small glass beaker was weighed and the mass was written down. Next, fresh berry fruits were transferred into the beaker. The mass was weighed again. Samples were put into a laboratory drier (condition $105^{\circ} \mathrm{C}$ ) and left there for $48 \mathrm{~h}$. After that time, the samples were transferred into a desiccator and left for the next $12 \mathrm{~h}$. The samples were weighed, and the total dry matter was calculated on the basis of mass differentiation, as described by Ohene and Maalekuu [29].

\subsection{Anthocyanin Separation and Identification}

Anthocyanins were measured by the HPLC method described by Ponder and Hallmann [30]. Freeze-dried berry fruit samples were extracted with $80 \%$ methanol. After first centrifugation (conditions: time $10 \mathrm{~min}, \mathrm{rpm} 6000$, temperature $30^{\circ} \mathrm{C}$ ), $2.5 \mathrm{~mL}$ of the supernatant was collected in a new plastic tube, and then $2.5 \mathrm{~mL}$ of $10 \mathrm{~mol} \mathrm{HCl}$ and $5 \mathrm{~mL}$ of $100 \%$ methanol were added. The samples were gently shaken (up and down) and put in a cold place $\left(5^{\circ} \mathrm{C}, 10 \mathrm{~min}\right)$. Next, $900 \mu \mathrm{L}$ of the extract was transferred into HPLC vials and analyzed. The anthocyanins were separated under isocratic conditions with a flow rate of $1.5 \mathrm{~mL} / \mathrm{min}$. One mobile phase, $5 \%$ acetic acid, methanol, and acetonitrile (70:10:20), was used. The HPLC set was performed from modules: two pumps (LC-20AD), one controller (CBM-20A), one column oven (SIL-20AC), one spectrometer (UV-VIS SPD-20 AV). Phenomenx Fusion 80-A $(4.6 \times 250 \mathrm{~mm}$, practical shape $4 \mu \mathrm{m})$, and one column (C18) were used. The analysis time was $15 \mathrm{~min}$ at a wavelength of $520 \mathrm{~nm}$. The anthocyanins were identified by using pure standards (Sigma-Aldrich, Poland) and the retention times for the standards. The limit of detection (LOD) and level of quantification (LOQ) for all quantified anthocyanin compounds are presented below (Table 1).

Table 1. LOD and LOQ values for all anthocyanins used in the presented experiment (mg/100 $\mathrm{g}$ f.w.).

\begin{tabular}{ccc}
\hline Compound & LOD & LOQ \\
\hline Cyanidin-3-O-glucoside & 0.4 & 1.2 \\
Cyanidin-3-O-rutinoside & 0.8 & 2.4 \\
Cyanidin-3-O-galactoside & 0.1 & 0.2 \\
Delphinidin-3-O-glucoside & 2.2 & 6.7 \\
Delphinidin-3-O-rutinoside & 1.0 & 3.0 \\
Delphinidin-3-O-galactoside & 1.0 & 3.0 \\
Pelargonidin-3-O-glucoside & 0.5 & 1.5 \\
Malvidin-3-O-galactoside & 0.8 & 2.4 \\
\hline
\end{tabular}

\subsection{Statistical Analysis}

The obtained results were statistically elaborated using Statgraphics Centurion 15.2.11.0 software (StatPoint Technologies, Inc., Warranton, VA, USA). PCA was performed with XLStat Trial version (Microsoft Excel). In tables, values represent the mean value for berry fruit cultivars: Tulnamen raspberry $(n=12)$, Darrow and Thornless Evergreen blackberries $(n=6)$; Detvan, Rovada, Heros, and Jonkheer van Tets red currants $(n=6)$; Ben Lomond and Titania blackcurrants $(n=3)$; and Coville, Blue Gold, and Brigitta highbush blueberries $(n=3)$. Statistical analysis was based on two-way variance analysis with the use of Tukey's 
test $(p=0.05)$. A lack of statistically significant differences between the examined groups was indicated by labeling with the same letters. A standard error (SE) was given for each mean value reported in the tables.

\section{Results}

\section{The Content of Anthocyanins in Different Berry Fruits}

Berry-type fruits represent potent sources of anthocyanin compounds, with strong health-promoting and disease-preventive properties. The pictures of identified anthocyanis are presented in Figure 2. The analysis of selected berries commonly consumed in Poland and other counties indicated that the species and cultivar have a significant influence on the anthocyanin content of the fruit. Anthocyanins are responsible for the specific dark color of berries. It is usually believed that the darker the fruit, the more anthocyanins it contains. Our results on the concentrations of anthocyanins (total and individual for the compounds determined chromatographically) in different species and cultivars of berries are presented in Tables 2 and 3. The results confirmed that the darkest species of berries contain the highest total anthocyanins. Among all tested species, blackberry and blackcurrant were characterized significantly $(p<0.0001)$ by the highest content of total anthocyanins (sum)

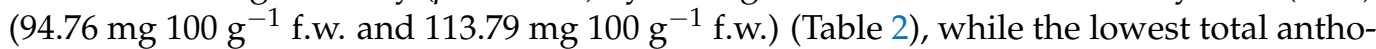
cyanin content was found in red currant fruits $\left(4.95 \mathrm{mg} 100 \mathrm{~g}^{-1}\right.$ f.w.). However, taking into account the influence of the cultivar on the total anthocyanin content in berries of different species and cultivars, the blackcurrant Titania cultivar accumulated the highest total anthocyanin content $\left(p<0.0001 ; 127.15 \mathrm{mg} 100 \mathrm{~g}^{-1}\right.$ f.w.) (Table 3). Blackberry was also characterized by the highest concentration of cyanidin-3-O-glucoside $(p<0.0001 ; 88.24 \mathrm{mg}$ $100 \mathrm{~g}^{-1}$ f.w.) among the other examined berry species, and individual cultivars of blackberries, Darrow and Thornless Evergreen, contained, respectively, $80.98 \mathrm{mg} 100 \mathrm{~g}^{-1}$ f.w. and

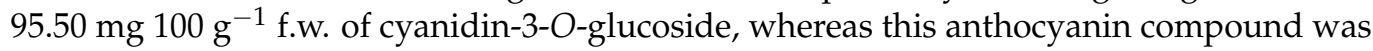
not detected in highbush blueberry.

However, in the case of pelargonidin-3-O-glucoside, this compound was only found in

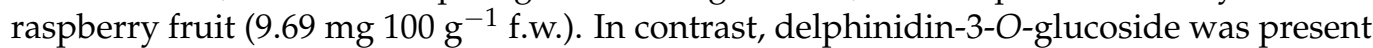
in both raspberry and blackcurrant fruits, but raspberries contained significantly more of

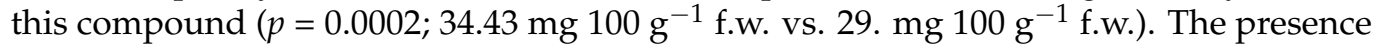
of delphinidin-3-O-rutinoside was found only in the blackcurrant samples, and the Ben Lomond cultivar contained $51.17 \mathrm{mg} 100 \mathrm{~g} \mathrm{~g}^{-1} \mathrm{f} . \mathrm{w}$. of this compound, while the Titania

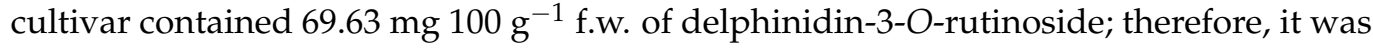
also concluded that the Titania cultivar is characterized significantly by a higher content of this compound $(p<0.0001)$. Cyanidin-3-O-rutinoside was detected in blackberry, red currant, and blackcurrant but not in raspberry and highbush blueberry. The blackcurrant

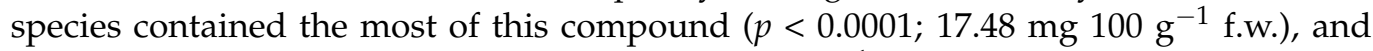

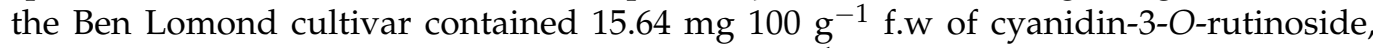

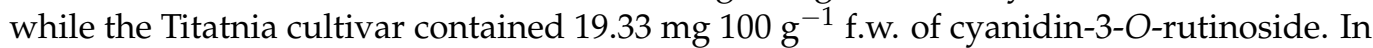
contrast, delphinidin-3-O-galactoside and malvidin-3-O-galactoside were detected only in the highbush blueberry fruit samples, and the other tested species did not contain these two compounds. Highbush blueberry contained an average $48.33 \mathrm{mg}^{100 \mathrm{~g}^{-1}}$ f.w. of malvinidin3-O-galactoside and $6.45 \mathrm{mg} 100 \mathrm{~g} \mathrm{~g}^{-1} \mathrm{f}$.w. of delphinidin-3-O-galactoside. Among all the examined highbush blueberry cultivars, the Coville cultivar contained the most malvinidin-

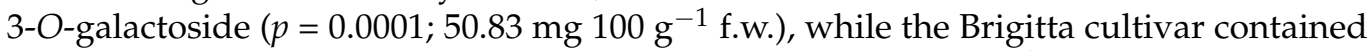

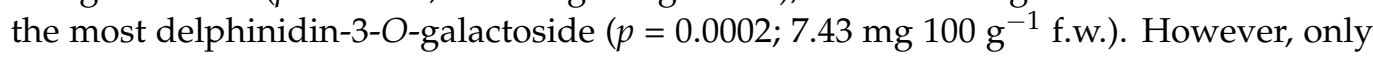
blackberries and highbush blueberries were distinguished by the concentration of cyanidin3-O-galactoside. Moreover, the highbush blueberry fruit contained significantly more of this compound than the blackberry fruit $\left(p<0.0001 ; 24.77 \mathrm{mg} 100 \mathrm{~g}^{-1}\right.$ f.w. vs. $0.40 \mathrm{mg}$ $100 \mathrm{~g}^{-1}$ f.w.). Comparing the cyanidin-3-O-galactoside content in the fruits of different cultivars of highbush blueberry, it was found that the fruits of the Brigitta cultivar contain the most of this compound ( $p<0.0001 ; 28.53 \mathrm{mg} 100 \mathrm{~g}^{-1} \mathrm{f}$.w.). 

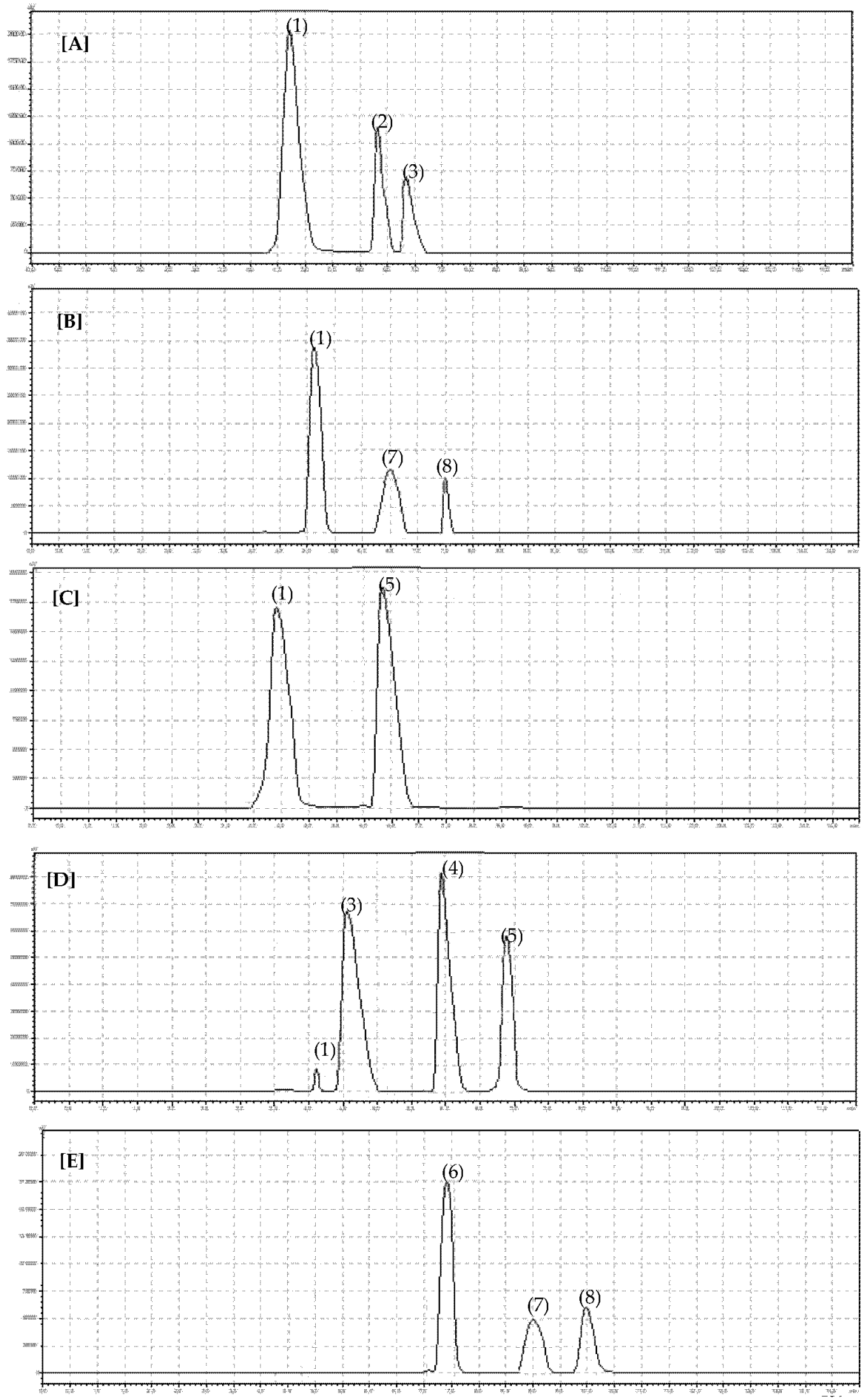

Figure 2. Chromatogram showing retention times for identified anthocyanins in examined berry fruits: (A) raspberry, (B) blackberry, (C) red currant, (D) blackcurrant, and (E) blueberry. (1) Cy-3-Glu, (2) Pel-3-Glu, (3) Del-3-Glu, (4) Del-3-Rut, (5) Cy-3-Rut, (6) Del-3-Gal, (7) Cy-3-Gal, and (8) Malv-3-Gal. 
Table 2. The average content of individual anthocyanins in different species of berry fruits (in $\mathrm{mg} 100 \mathrm{~g}^{-1} \mathrm{f}$.w.). Mean value $\pm \mathrm{SE}$.

\begin{tabular}{|c|c|c|c|c|c|c|c|c|c|}
\hline Species & TA & Cy-3-Glu & Pel-3-Glu & Del-3-Glu & Del-3-Rut & Cy-3-Rut & Del-3-Gal & Cy-3-Gal & Malv-3-Gal \\
\hline $\begin{array}{c}\text { Raspberry } \\
\text { (Rubus ideus L.) }\end{array}$ & $89.54 \pm 3.02 \mathrm{ab}$ & $45.42 \pm 1.54 b$ & $9.69 \pm 0.45$ & $34.43 \pm 1.17 \mathrm{a}$ & $<\mathrm{LOD}$ & $<\mathrm{LOD}$ & $<\mathrm{LOD}$ & $<\mathrm{LOD}$ & $<\mathrm{LOD}$ \\
\hline $\begin{array}{l}\text { Blackberry } \\
\text { (Rubus L.) }\end{array}$ & $94.76 \pm 3.16 a$ & $88.24 \pm 2.97 a$ & $<\mathrm{LOD}$ & $<\mathrm{LOD}$ & $<\mathrm{LOD}$ & $6.12 \pm 0.22 b$ & $<\mathrm{LOD}$ & $0.40 \pm 0.02 b$ & $<\mathrm{LOD}$ \\
\hline $\begin{array}{l}\text { Red currant } \\
\text { (Ribes L.) }\end{array}$ & $4.95 \pm 0.24 c$ & $1.94 \pm 0.09 \mathrm{c}$ & $<\mathrm{LOD}$ & $<\mathrm{LOD}$ & $<\mathrm{LOD}$ & $3.00 \pm 0.16 b$ & $<\mathrm{LOD}$ & $<\mathrm{LOD}$ & $<\mathrm{LOD}$ \\
\hline $\begin{array}{c}\text { Blackcurrant } \\
\text { (Ribes nigrum L.) }\end{array}$ & $113.79 \pm 5.46 a$ & $6.54 \pm 0.43 c$ & $<\mathrm{LOD}$ & $29.36 \pm 1.34 b$ & $60.40 \pm 3.75$ & $17.48 \pm 0.76 a$ & $<\mathrm{LOD}$ & $<\mathrm{LOD}$ & $<$ LOD \\
\hline $\begin{array}{l}\text { Highbush blueberry } \\
\text { (Vaccinium corymbosum L.) }\end{array}$ & $79.55 \pm 1.18 \mathrm{~b}$ & $<\mathrm{LOD}$ & $<\mathrm{LOD}$ & $<\mathrm{LOD}$ & $<\mathrm{LOD}$ & $<\mathrm{LOD}$ & $6.45 \pm 0.28$ & $24.77 \pm 0.93 a$ & $48.33 \pm 0.69$ \\
\hline$p$-Value (species) & $<0.0001$ & $<0.0001$ & & 0.0002 & & $<0.0001$ & & $<0.0001$ & \\
\hline
\end{tabular}

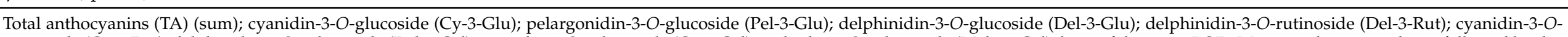

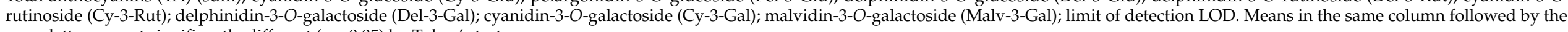
same letter are not significantly different $(p<0.05)$ by Tukey's test. 
Table 3. The content of individual anthocyanins in different cultivars of berry fruits (in $\mathrm{mg} 100 \mathrm{~g}^{-1}$ f.w.). Mean value \pm SE.

\begin{tabular}{|c|c|c|c|c|c|c|c|c|c|c|}
\hline Species & Cultivar & TA & Cy-3-Glu & Pel-3-Glu & Del-3-Glu & Del-3-Rut & Cy-3-Rut & Del-3-Gal & Cy-3-Gal & Malv-3-Gal \\
\hline $\begin{array}{c}\text { Raspberry } \\
\text { (Rubus ideus L.) }\end{array}$ & Tulnameen & $89.54 \pm 3.02 \mathrm{bcd}$ & $45.42 \pm 1.54 \mathrm{~b}$ & $9.69 \pm 0.45 a$ & $34.43 \pm 1.17 a$ & $<\mathrm{LOD}$ & $<\mathrm{LOD}$ & $<\mathrm{LOD}$ & $<\mathrm{LOD}$ & $<\mathrm{LOD}$ \\
\hline \multirow{2}{*}{$\begin{array}{l}\text { Blackberry } \\
\text { (Rubus L.) }\end{array}$} & Darrow & $87.02 \pm 0.37 \mathrm{bcde}$ & $80.98 \pm 0.25 a$ & $<$ LOD & $<\mathrm{LOD}$ & $<\mathrm{LOD}$ & $5.70 \pm 0.18 c$ & $<\mathrm{LOD}$ & $0.35 \pm 0.01 \mathrm{~d}$ & $<\mathrm{LOD}$ \\
\hline & Thornless Evergreen & $102.50 \pm 0.09 b$ & $95.50 \pm 0.12 \mathrm{a}$ & $<\mathrm{LOD}$ & $<\mathrm{LOD}$ & $<$ LOD & $6.55 \pm 0.18 c$ & $<\mathrm{LOD}$ & $0.45 \pm 0.02 \mathrm{~d}$ & $<\mathrm{LOD}$ \\
\hline \multirow{4}{*}{$\begin{array}{l}\text { Red currant } \\
\text { (Ribes L.) }\end{array}$} & Detvan & $4.39 \pm 0.32 \mathrm{e}$ & $1.73 \pm 0.08 c$ & $<\mathrm{LOD}$ & $<\mathrm{LOD}$ & $<\mathrm{LOD}$ & $2.66 \pm 0.24 \mathrm{~d}$ & $<\mathrm{LOD}$ & $<\mathrm{LOD}$ & $<\mathrm{LOD}$ \\
\hline & Rovada & $4.89 \pm 0.40 \mathrm{e}$ & $1.92 \pm 0.13 c$ & $<\mathrm{LOD}$ & $<\mathrm{LOD}$ & $<\mathrm{LOD}$ & $2.97 \pm 0.2 \mathrm{~d}$ & $<\mathrm{LOD}$ & $<\mathrm{LOD}$ & $<\mathrm{LOD}$ \\
\hline & Heros & $4.30 \pm 0.1 \mathrm{e}$ & $1.60 \pm 0.01 c$ & $<\mathrm{LOD}$ & $<\mathrm{LOD}$ & $<\mathrm{LOD}$ & $2.70 \pm 0.14 \mathrm{~d}$ & $<\mathrm{LOD}$ & $<\mathrm{LOD}$ & $<\mathrm{LOD}$ \\
\hline & Jonkheer van Tets & $6.20 \pm 0.26 \mathrm{e}$ & $2.52 \pm 0.13 c$ & $<\mathrm{LOD}$ & $<\mathrm{LOD}$ & $<\mathrm{LOD}$ & $3.68 \pm 0.13 b$ & $<\mathrm{LOD}$ & $<\mathrm{LOD}$ & $<\mathrm{LOD}$ \\
\hline \multirow{2}{*}{$\begin{array}{l}\text { Blackcurrant } \\
\text { (Ribes nigrum L.) }\end{array}$} & Ben Lomond & $100.43 \pm 0.39 \mathrm{bc}$ & $7.54 \pm 0.23 c$ & $<\mathrm{LOD}$ & $26.07 \pm 0.10 \mathrm{~b}$ & $51.17 \pm 0.39 b$ & $15.64 \pm 0.18 \mathrm{a}$ & $<\mathrm{LOD}$ & $<\mathrm{LOD}$ & $<\mathrm{LOD}$ \\
\hline & Titania & $127.15 \pm 0.43 a$ & $5.55 \pm 0.15 c$ & $<\mathrm{LOD}$ & $32.64 \pm 0.01 \mathrm{ab}$ & $69.63 \pm 0.25 a$ & $19.33 \pm 0.03 a$ & $<\mathrm{LOD}$ & $<\mathrm{LOD}$ & $<\mathrm{LOD}$ \\
\hline \multirow{3}{*}{$\begin{array}{l}\text { Highbush blueberry } \\
\text { (Vaccinium corymbosum L.) }\end{array}$} & Coville & $78.25 \pm 0.48 \mathrm{de}$ & $<\mathrm{LOD}$ & $<\mathrm{LOD}$ & $<\mathrm{LOD}$ & $<\mathrm{LOD}$ & $<\mathrm{LOD}$ & $5.41 \pm 0.12 c$ & $22.02 \pm 0.36 c$ & $50.83 \pm 0.16 a$ \\
\hline & Blue Gold & $76.14 \pm 0.62 d$ & $<\mathrm{LOD}$ & $<\mathrm{LOD}$ & $<\mathrm{LOD}$ & $<\mathrm{LOD}$ & $<\mathrm{LOD}$ & $6.52 \pm 0.12 b$ & $23.75 \pm 0.06 \mathrm{~b}$ & $45.87 \pm 0.44 \mathrm{c}$ \\
\hline & Brigitta & $84.25 \pm 0.16$ cde & $<\mathrm{LOD}$ & $<\mathrm{LOD}$ & $<\mathrm{LOD}$ & $<\mathrm{LOD}$ & $<\mathrm{LOD}$ & $7.43 \pm 0.11 a$ & $28.53 \pm 0.07 \mathrm{a}$ & $48.29 \pm 0.07 \mathrm{~b}$ \\
\hline \multicolumn{2}{|c|}{$p$-Value (cultivar) } & $<0.0001$ & $<0.0001$ & $<0.0001$ & 0.0099 & $<0.0001$ & $<0.0001$ & 0.0002 & $<0.0001$ & 0.0001 \\
\hline
\end{tabular}

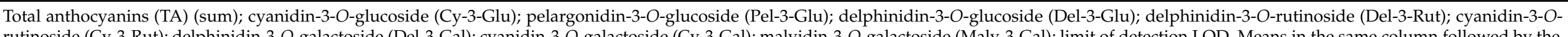

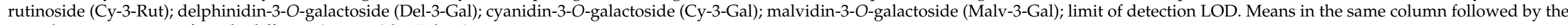

same letter are not significantly different $(p<0.05)$ by Tukey's test. 
PCA results showed that the overall degree of variability explained by PC1 and PC2 is $94.8 \%$ (Figure 3). This was confirmed by a strong link between the measured and identified anthocyanins and the examined berry fruits species. It is worth to point out that different berry fruits species are located in separate parts of the graph. Total anthocyanins as well mostly rutinoside derivates were more characterized in blackcurrant. In the case of galactoside derivates, we found a strong correlation with blueberry. In the last group, we found anthocyanins glucosides mostly characterized in raspberry and blackberry.

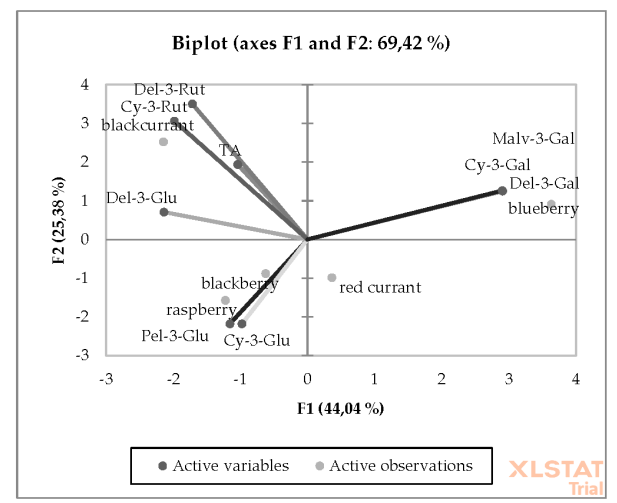

Figure 3. PCA showing the relationship between the anthocyanin content of different berry fruit species: total anthocyanins (TA), cyanidin-3-O-glucoside (Cy-3-Glu), pelargonidin-3-O-glucoside (Pel3-Glu), delphinidin-3-O-glucoside (Del-3-Glu), delphinidin-3-O-rutinoside (Del-3-Rut), cyaidin-3-Orutinoside (Cy-3-Rut), delphinidin-3-O-galactoside (Del-3-Gal), cyanidin-3-O-galactoside (Cy-3-Gal), and malvidin-3-O-galactoside (Malv-3-Gal).

The dendrogram received from hierarchical cluster analysis is shown in Figure 4 . Figure 4 shows the level of genetic similarity of the berry fruit species (A2) or cultivars (A1). The higher the scale value for cultivars or species, the greater the variety between them. In terms of the content of anthocyanin compounds, blackberry and red currant form a group that can be described as homogeneous. The same applies to varieties similar to each other: blackcurrant Ben Lomond and Titania cv. are similar; likewise highbush blueberry Coville and Brigitta cv. are even more similar.
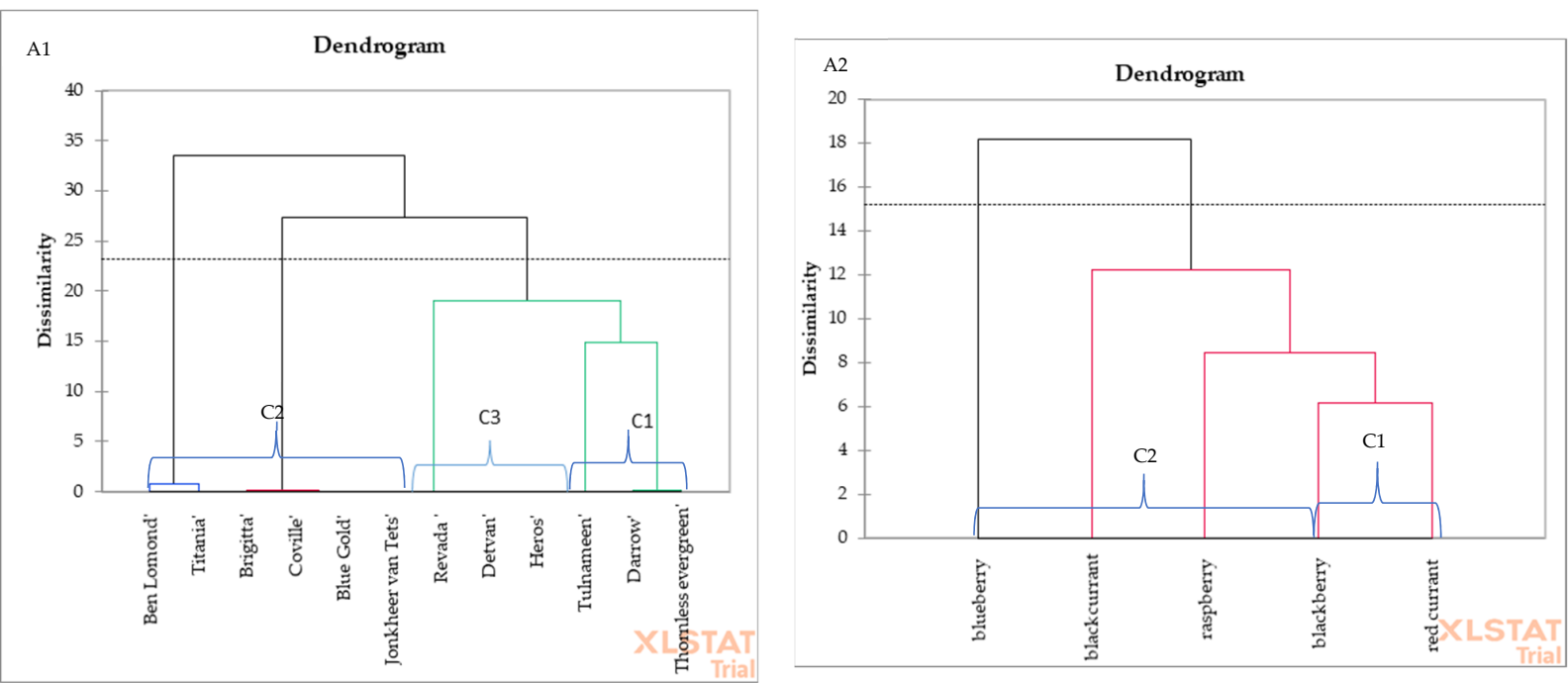

Figure 4. Cluster dendrograms for the berry fruit species (A2) (raspberry (Rubus ideus L.), blackberry (Rubus L.), red currant (Ribes L.), blackcurrant (Ribes nigrum L.), highbush blueberry (Vaccinium corymbosum L.)) or cultivars (A1) (raspberry (Rubus ideus L. Tulnameen cv.), blackberry (Rubus L. Darrow and Thornless Evergreen cv.), red currant (Ribes L. Detvan, Rovada, Heros, and Jonkheer van Tets cv.), blackcurrant (Ribes nigrum L. Ben Lomond and Titania cv.), highbush blueberry (Vaccinium corymbosum L., Coville, Blue Gold, and Brigitta cv.)). 
The hierarchical cluster analysis was performed to group berry fruit samples from different species or cultivars. The clustering of sample types regarding the composition of anthocyanin compounds grouped berry fruit species into two different groups ( $\mathrm{C} 1$ and C2) and berry fruit cultivars into three different groups (C1, C2, and C3). Therefore, this result shows that the two clusters in the case of the species and the three clusters in the case of the cultivar have different chemical compositions in terms of anthocyanin compounds. Cluster 1 (Figure 4A1) demonstrates that blackberry and red currant samples were grouped closely due to contents of anthocyanins, whereas raspberry, blackcurrant, and highbush blueberry formed cluster 2 (C2) in the dendrogram (Figure 4A1). However, as can be seen in the Figure 4A2 dendrogram, Tulameen, Darrow, and Thornless evergreen cv. were grouped closely (C1); Ben Lomond, Titania, Brigitta, Coville, Blue Gold, and Jonkeer van Teets cv. formed cluster 2 (C2) in the dendrogram; and Revada, Detvan, and Heros cv. samples were grouped into cluster 3 (C3) due to similar chemical composition in terms of the content of anthocyanins.

\section{Discussion}

As mentioned in the introductory section, anthocyanins belong to the flavonoids, a class of compounds with strong antioxidant properties. The past few decades have seen a steady increase in consumer interest in all fruit species rich in bioactive compounds with antioxidant activity beneficial to health, as well as in research on these compounds [31]. Berries are of special importance among other fruits due to their unique organoleptic properties, such as color, taste, and smell; exceptionally rich nutritional value; and the possibility of various applications in gastronomy and the food industry. They can be used in fresh and processed forms in the human diet $[19,32]$. According to FAOSTAT statistics, the total berry production has increased gradually over the years, and the latest data for 2019 show that the world production volume of berries amounts to 922,681 metric tons. Asia and the Americas are currently the continents with the largest production of berries, followed by Europe. Among the countries, China is the largest producer of fresh berries in the world, while the EU's top producers of berries are Spain, Germany, Italy, and Poland. Berries represent an important type of fresh produce in these countries in terms of production volume and economics [33]. At the same time, various species of berry are widespread on all continents; therefore, their importance is even greater because they are widely available and can be easily used in the diet [34]. As Poland is the leading producer of raspberries and currants in Europe, Germany of currants and gooseberries, Italy of blackberries, raspberries, and blueberries, and Spain has gained the top position in blueberry production [33], these species of berries have become the main sources of anthocyanins in the diet of Europeans. Therefore, in our research, we focused on comparing the anthocyanin content of these commonly cultivated species in Europe and some cultivars of these berries. Only 6 anthocyanins are widely spread in nature, although about 30 of these compounds have been described. Commonly occurring are pelargonidin, cyanidin, delphinidin, peonidin, petunidin, and malvinidin [19], which are the most common pigments in nature being responsible for the color of plant tissues [8].

In our study on raspberry fruits, the anthocyanin profile was predominated by cyanidin3-glucoside, which accounted for around $51 \%$ of total anthocyanins, followed by delphinidin3-O-glucoside, which accounted for 38\%, and pelargonidin-3-O-gucoside, which accounted for $11 \%$. Veberic and coauthors reported that this species contained the highest amounts of cyanidin glycosides $(83.8 \%)$, followed by pelargonidin glucosides $(16.2 \%)$, and thus, the color of the raspberry fruit is bright red. According to the authors, berry species contain two to six different cyanidin glycosides [35]. The anthocyanin profile, specific and characteristic to raspberry fruits, defined by Määttä-Riihinen et al. [36], consists of cyanidin-3-sophoroside, cyanidin-3-glucoside, cyandin-3-rutinoside, and cyanidin-3-glucoside-r-utinoside. These findings are in line with the results presented by Veberic et al. [35], who reported that cyanidin 3-sophoroside is the main cyanidin gycoside occurring in raspberries. In the study conducted by Corderio et al. [37], the anthocyanin profile of the raspberry samples was as 
follows: cyjanidin-3-sophoroside, cyjanidin-3(2-glucosylrutinoside), cyjanidin-3-glucoside, pelargonidin-3-sophoroside, and cyjanidin-3-rutinoside. The Tulnameen cultivar tested in our study contained $89.54 \mathrm{mg} 100 \mathrm{~g}^{-1}$ f.w. of anthocyanins. Generally, this is in agreement with the previously reported data. Babinaite et al. [38] reported that among the 17 redfruited raspberry cultivars, the anthocyanin content ranged from 29.2 to $130.6 \mathrm{mg} 100 \mathrm{~g}^{-1}$ f.w. Similar results were obtained by Weber and coauthors [39] comparing 30 cultivars, who showed the contents of anthocyanin being in the range from 35 to $112 \mathrm{mg} 100 \mathrm{~g}^{-1}$ f.w., expressed as cyjanidin-3-glucoside.

In blackberry fruits, we identified cyjanidin-3-O-glucoside as a predominant compound with a share of $93 \%$ of all anthocyanins detected, while $6.5 \%$ was cyjanidin-3$\mathrm{O}$-rutinoside and the rest $0.4 \%$ was cyjanidin-3-O-galactoside. Anthocyanins occurring in blackberry are mainly cyanidin-based anthocyanins, and the primary anthocyanin is cyanidin-3-O-glucoside [40]. Some authors also reported the detection of various other anthocyanins in blackberries, such as cyanidin-3-O-xyloside, cyanidin-3-O-dioxaloylglucoside, and cyanidin-3-O-(600-malonyl)-glucoside, as well as pelargonidin-3-O-glucoside, malvidin3-O-glucoside, cyanidin-3-O-arabinoside, cyanidin-3-O-xyloside, cyanidin-3-O-rutinoside, cyanidin-3-O-dioxalylglucoside, and cyanidin-3-O-glucoside acylated with malonic acid in smaller amounts [41]. The total anthocyanin content of blackberry fruits detected in our study ranged approximately from 87 to $102 \mathrm{mg} 100 \mathrm{~g}^{-1} \mathrm{f}$.w. This is quite similar to the

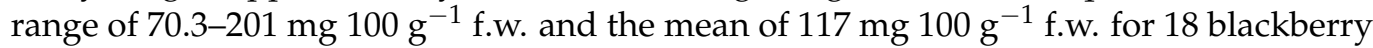
cultivars reported by Fan-Chiang and Wrolstad [42] but somewhat lower than Van de Velde et al.'s [40] work, who revealed the concentration of anthocyanins in the three blackberry cultivars at a level ranging from $107 \mathrm{mg}$ to $124 \mathrm{mg}$ in $100 \mathrm{~g}$ of fresh matter. Our results showed that the Tornless Evergreen cultivar produces a larger amount of anthocyanins than the thorny one, Darrow, which is consistent with Koloniak-Ostek et al.'s [0] report. In the

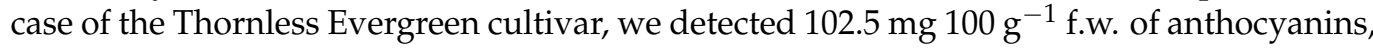
which is similar to the content shown by Fan-Chiang and Wrolstad, who reported in the same cultivar the amount of $117 \mathrm{mg} 100 \mathrm{~g}^{-1}$ f.w. [42]. According to another study, Thornless Evergreen berries contain a higher anthocyanin content expressed as cyanidin-3-glucoside

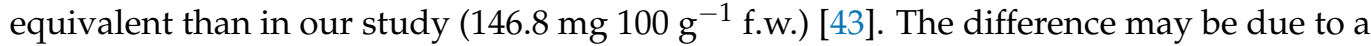
different method of anthocyanin determination. The previously mentioned authors [42] detected five anthocyanins in blackberries: cyanidin-3-glucoside, cyanidin-3-rutinoside, cyanidin-3-xyloside, cyanidin-3-glucoside acylated with malonic acid, and an unidentified acylated derivative of cyanidin-3-glucoside, while Van de Velde and coauthors detected four cyjanidin-based compounds, and cyanidin-3-O-glucoside was the major anthocyanin detected in all blackberry samples, representing more than $85 \%$ of the total anthocyanins. This finding is in agreement with our results and with the reports for other blackberry cultivars [42]. The papers of Jordheim et al. [44] and Veberic et al. [35], who notified that blackberries only biosynthesize cyanidin glycosides as primary metabolites, also confirm our results on the identified anthocyanins in blackcurrant fruit.

In the case of red currants, cyanidin glycosides are the only group of anthocyanins present in the berries [35]. According to our results, the sum of anthocyanins detected

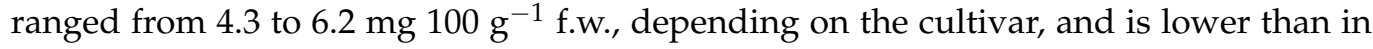
Zdunic and coauthors' research [45]. The authors reported an anthocyanin content from 7.1 to $19.3 \mathrm{mg} 100 \mathrm{~g}^{-1}$ f.w. in individual cultivars of red currant. In the case of Rovada and Jonkheer van Tets cultivars, which we also analyzed, the contents were 8.2 and $18.8 \mathrm{mg}$

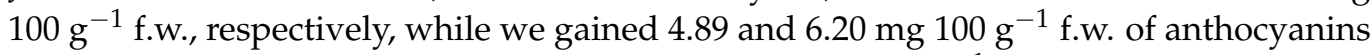

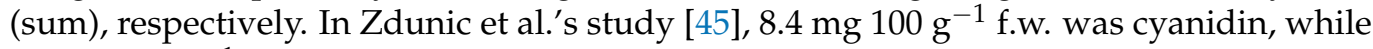
$5.3 \mathrm{mg} 100 \mathrm{~g}^{-1}$ f.w. was delphinidin in the Rovada cultivar. At the same time, in Jonkheer van Tets, $16.0 \mathrm{mg} 100 \mathrm{~g}^{-1}$ f.w. was cyanidin, while $4.3 \mathrm{mg} 100 \mathrm{~g}^{-1} \mathrm{f}$.w. was delphinidin. Other authors [43] reported the anthocyanin content expressed as cyanidin-3-glucoside equivalents in the Rovada cultivar on the level of $7.5 \mathrm{mg} 100 \mathrm{~g}^{-1}$ f.w. In our study, in all three cultivars of red currants tested, we detected only two anthocyanin compounds, cyanidin-3-O-rutinoside and cyanidin-3-O-glucoside, and the first one accounted for about 
$60 \%$. Borges et al. [46] also reported that the main anthocyanins in the red currant extract were cyanidin-3-O- rutinoside and cyanidin-3-O-rutinoside.

In our study, delphinidins (delphinidin-3-O-glucoside and delphinidin-3-O-rutinoside) were dominating anthocyanins in blackcurrants, constituting $76.1 \%$ and $80.5 \%$ of the sum of anthocyanins detected, respectively, depending on the cultivar. This corresponds to other authors' reports on the anthocyanin profile of blackcurrants. According to Veberic et al. [35], delphinidin has the highest share (60.7\%) in blackcurrant anthocyanins, followed by cyanidin $(30.6 \%)$ and peonidin $(0.9 \%)$. Other authors have reported the highest share of delphinidin-3-O-rutinoside and cyanidin-3-O-rutinoside, followed by delphinidin3-O-glucoside in blackcurrants [47]. This result was in accordance with other studied references [45,48-50]. Laczko-Zold et al. [51] in their study detected as the prevailing anthocyanin cyanidin-3-O-glucoside ( $82.7 \%$ share) in blackcurrant fruits. The mean value of the sum of four anthocyanins detected in two blackcurrant cultivars was $113.79 \mathrm{mg} 100 \mathrm{~g}^{-1} \mathrm{f} . \mathrm{w}$., which is in agreement with that reported in the literature [48,52], but some authors have reported a higher total anthocyanin content expressed as milligrams of cyanidin-3-glucoside per $100 \mathrm{~g}$ of f.w. in blackcurrants [53]. In our study, two cultivars Titania and Ben Lomond were tested, and the higher anthocyanin content was found in the Titania cultivar (127.15 mg $100 \mathrm{~g}^{-1}$ f.w.) in comparison to the other one $\left(100.43 \mathrm{mg} 100 \mathrm{~g}^{-1} \mathrm{f}\right.$.w.). These results are partly confirmed by studies of other authors. Wojdyło et al. [48] reported a similar anthocyanin content in the Titania cultivar, but Benvenuti et al. [53] revealed twofold more anthocyanins in the Ben Lomond cultivar.

Blueberries are referred to as a fruit that guarantees longevity due to the fact that they are considered one of the greatest sources of antioxidants of all fruits and vegetables [31]. They belong to berries with a high content of anthocyanins, which is confirmed by many studies included in the review by Gündeşli et al., according to which the content of these compounds in the fruit ranges from 57 to $503 \mathrm{mg} 100 \mathrm{~g}^{-1}$ f.w. [31]. These results are in alignment with our findings and suggest varietal differences in the anthocyanin content of blueberry fruits. The other studies [54-57] confirmed that the values resulting from the quantitative analysis of total anthocyanins in blueberries are in a quite wide range and are strongly dependent on the blueberry cultivar and on the method used for analysis. Additionally, as Skrovankova et al. [57] underline, the phenolics, in that the anthocyanin content of blueberries, are influenced by the degree of maturity at harvest, as well as growing practices and growing locations. During blueberry ripening, polyphenols are transformed toward the synthesis of anthocyanins, which may confirm the above statements. Another reason for the big differences in the anthocyanin content of blueberries may also be the size of the fruit. Anthocyanins occur mostly in the blueberry skin, so the small-sized fruits have a relatively higher skin area and, thus, a higher anthocyanin content [58]. Compositional analysis of the anthocyanins in seven cultivars of blueberries [55] showed that malvinidin is the major anthocyanin component of fruits (representing $30-47 \%$ of the total anthocyanins). Stevenson and Scalzo [58] in their review also summarized that the predominating anthocyanin in blueberries is malvidin, followed by delphinidin, cyanidin, petunidin, and pelargonidin in similar quantities. In our study, the most abundant anthocyanins were malvinidin-3-O-galactoside $(60.8 \%)$ and cyanidin-3-O-galactoside $(31.1 \%)$, while delphinidin-3-O-galactoside, on average, constituted $8.1 \%$ of anthocyanins in three cultivars tested. The long-term evaluation of the anthocyanin composition of blueberries belonging to over 80 cultivars showed a significant variability related to the vegetation seasons and between cultivars [58]. We found a similar content of anthocyanins in the three

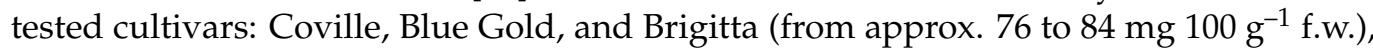
which was quite consistent with the amount of these compounds in the same cultivars included in the works of Stevenson and Scalzo, which were 100, 206, and $101.8 \mathrm{mg}$ of $100 \mathrm{~g}^{-1}$ f.w., respectively [58].

The described observations on the level of the content of detected anthocyanins in the berry fruits and PCA allow us to conclude that individual compounds are closely correlated with the species of berries. Dark-colored blackcurrants contain mainly delphinidin-3-O- 
rutinoside and cyanidin-3-O-rutinoside, while red currants, which have much brighter fruits than blackcurrant, have the lowest content of anthocyanins of all the berries tested. On the other hand, for botanically related blackberries and raspberries, the most characteristic are the same compounds such cyanidin-3-O-glucoside and pelargonidin-3-O-glucoside. In addition, in the case of blueberries, there is a clear correlation with anthocyanin compounds such as delphinidin-3-O-galactoside, cyanidin-3-O-galactoside, and malvidin-3-O-galactoside, which are not found in other berries in such high amounts. These results have also been confirmed by other authors in studies of anthocyanin components in fruits [37,42,46,52,59]. According to the literature, fruit, berries, and red wine are most frequently reported as contributing foods to dietary anthocyanin intake, which varies depending on the country, season, and dietary habits [34,59]. In contrast, berries of numerous species and cultivars eaten by consumers contain anthocyanins in far greater quantities than other food representatives such as wine [59]. To summarize our findings, the average amount of anthocyanins in berry fruits investigated is in the following increasing order: red currant $<$ blueberry $<$ raspberry, red $<$ blackberry $<$ blackcurrant. This indicates that last three mentioned berries are significant sources of anthocyanins, which is consistent with findings of other authors cited above. The differences between different berry species in the content of anthocyanins are closely associated with the color of their skin. Berries with red, blue, or purple colors belong to one of the most important sources of anthocyanins, which occur mainly in the external layers of the skin, while flesh tissues (in vacuoles in the form of granules) contain much less or no anthocyanins [35]. This is the explanation that light-colored fruits like red currants have less anthocyanins in their composition. Additionally, some of the above-described differences in anthocyanin content and composition within individual berry species are due to the fact that the chemical composition of plants is influenced by various factors like cultivar and tissue, cultivation method, climatic conditions of the growing area, as well as ripening stage of berries and storage conditions $[36,46,49,53]$. The mentioned discrepancies indicate that the quantitative and qualitative profiles of anthocyanins occurring in berries may vary significantly depending on these factors. This can also be related to the method of anthocyanin detection, as the works cited sometimes differed in this respect.

\section{Conclusions}

The study showed that the species and cultivars of berry fruits differ significantly in the content of anthocyanin compounds. The darkest species of berries contain the highest total anthocyanins. Among all the tested samples, blackberry and blackcurrant were significantly characterized by the highest total anthocyanin content, with the lowest being in red currant fruit. Additionally, the content of individual anthocyanin compounds in particular species and cultivars also varied. Although different species and cultivars of berry fruits show a high variability in anthocyanin profiles, they all should be recognized as a rich source of bioactive compounds with pro-health potential. This study expands our knowledge about the variation in the content of valuable anthocyanins in berry fruits and may help in the selection and validation of the most productive species. More work is needed on identifying, quantifying, and decoding anthocyanins in fruits of different berry species and cultivars, in that in the skin, flesh, and seeds of these berries.

Author Contributions: Conceptualization, A.P., E.H., R.K., and D.Ś.-T.; methodology, A.P. and E.H.; formal analysis, A.P., M.K. and E.H.; investigation, A.P., E.H., M.K., R.K., and D.Ś.-T.; data curation, A.P., E.H., R.K., and D.Ś.-T.; writing-original draft preparation, A.P., E.H., and R.K.; writing-review and editing, R.K. and D.Ś-T.; visualization, A.P. and E.H. All authors have read and agreed to the published version of the manuscript.

Funding: The study was funded by the Polish Ministry of Education and Science with funds of the Institute of Human Nutrition Sciences, Warsaw University of Life Sciences (WULS), for scientific research.

Institutional Review Board Statement: Not applicable.

Informed Consent Statement: Not applicable. 
Data Availability Statement: Data will be made available upon reasonable request by authors Alicja Ponder and Ewelina Hallmann.

Conflicts of Interest: The authors declare no conflict of interest. The funders had no role in the design of the study; in the collection, analyses, or interpretation of data; in the writing of the manuscript; or in the decision to publish the results.

\section{References}

1. García-Gómez, B.E.; Salazar, J.A.; Nicolás-Almansa, M.; Razi, M.; Rubio, M.; Ruiz, D.; Martínez-Gómez, P. Molecular Bases of Fruit Quality in Prunus Species: An Integrated Genomic, Transcriptomic, and Metabolic Review with a Breeding Perspective. Int. J. Mol. Sci. 2020, 22, 333. [CrossRef] [PubMed]

2. Kaume, L.; Howard, L.R.; Devareddy, L. The Blackberry Fruit: A Review on Its Composition and Chemistry, Metabolism and Bioavailability, and Health Benefits. J. Agric. Food Chem. 2011, 60, 5716-5727. [CrossRef] [PubMed]

3. Mannino, G.; Gentile, C.; Ertani, A.; Serio, G.; Bertea, C. Anthocyanins: Biosynthesis, Distribution, Ecological Role, and Use of Biostimulants to Increase Their Content in Plant Foods-A Review. Agriculture 2021, 11, 212. [CrossRef]

4. Krishnan, V.; Rani, R.; Pushkar, S.; Lal, S.K.; Srivastava, S.; Kumari, S.; Vinutha, T.; Dahuja, A.; Praveen, S.; Sachdev, A. Anthocyanin fingerprinting and dynamics in differentially pigmented exotic soybean genotypes using modified HPLC-DAD method. J. Food Meas. Charact. 2020, 14, 1966-1975. [CrossRef]

5. Krüger, S.; Morlock, G.E. Fingerprinting and characterization of anthocyanins in 94 colored wheat varieties and blue aleurone and purple pericarp wheat crosses. J. Chromatogr. A 2018, 1538, 75-85. [CrossRef]

6. Mannino, G.; Di Stefano, V.; Lauria, A.; Pitonzo, R.; Gentile, C. Vaccinium macrocarpon (Cranberry)-Based Dietary Supplements: Variation in Mass Uniformity, Proanthocyanidin Dosage and Anthocyanin Profile Demonstrates Quality Control Standard Needed. Nutrients 2020, 12, 992. [CrossRef]

7. Da Silva, F.L.; Escribano-Bailón, M.T.; Alonso, J.J.P.; Rivas-Gonzalo, J.C.; Santos-Buelga, C. Anthocyanin pigments in strawberry. LWT 2007, 40, 374-382. [CrossRef]

8. Castañeda-Ovando, A.; Pacheco-Hernández, M.D.L.; Páez-Hernández, M.E.; Rodríguez, J.A.; Galán-Vidal, C.A. Chemical studies of anthocyanins: A review. Food Chem. 2009, 113, 859-871. [CrossRef]

9. Tanaka, Y.; Sasaki, N.; Ohmiya, A. Biosynthesis of plant pigments: Anthocyanins, betalains and carotenoids. Plant J. 2008, 54, 733-749. [CrossRef]

10. Cisowska, A.; Wojnicz, D.; Hendrich, A.B. Anthocyanins as Antimicrobial Agents of Natural Plant Origin. Nat. Prod. Commun. 2011, 6, 149-156. [CrossRef] [PubMed]

11. Robert, P.; Fredes, C. The Encapsulation of Anthocyanins from Berry-Type Fruits. Trends in Foods. Molecules 2015, 20, 5875-5888. [CrossRef]

12. Wallace, T.C. Anthocyanins in cardiovascular disease prevention. In Anthocyanins in Health and Disease; CRC Press: Boca Raton, FL, USA, 2013; pp. 165-197. [CrossRef]

13. Mekapogu, M.; Vasamsetti, B.M.K.; Kwon, O.-K.; Ahn, M.-S.; Lim, S.-H.; Jung, J.-A. Anthocyanins in Floral Colors: Biosynthesis and Regulation in Chrysanthemum Flowers. Int. J. Mol. Sci. 2020, 21, 6537. [CrossRef] [PubMed]

14. Huang, W.-Y.; Davidge, S.T.; Wu, J. Bioactive Natural Constituents from Food Sources-Potential Use in Hypertension Prevention and Treatment. Crit. Rev. Food Sci. Nutr. 2013, 53, 615-630. [CrossRef]

15. Frank, K.; Köhler, K.; Schuchmann, H.P. Stability of anthocyanins in high pressure homogenisation. Food Chem. 2012, 130, 716-719. [CrossRef]

16. Fernández-López, J.A.; Angosto, J.M.; Giménez, P.J.; León, G. Thermal Stability of Selected Natural Red Extracts Used as Food Colorants. Plant Foods Hum. Nutr. 2013, 68, 11-17. [CrossRef] [PubMed]

17. Liu, Y.; Tikunov, Y.; Schouten, R.E.; Marcelis, L.F.M.; Visser, R.G.F.; Bovy, A. Anthocyanin Biosynthesis and Degradation Mechanisms in Solanaceous Vegetables: A Review. Front. Chem. 2018, 6, 52. [CrossRef] [PubMed]

18. Holme, I.B.; Dionisio, G.; Brinch-Pedersen, H. A Roadmap to Modulated Anthocyanin Compositions in Carrots. Plants 2021, 10, 472. [CrossRef]

19. Seeram, N.P. Berry Fruits: Compositional Elements, Biochemical Activities, and the Impact of Their Intake on Human Health, Performance, and Disease. J. Agric. Food Chem. 2008, 56, 627-629. [CrossRef]

20. Nile, S.H.; Park, S.W. Edible berries: Bioactive components and their effect on human health. Nutrition 2014, 30, 134-144. [CrossRef] [PubMed]

21. Olas, B. Berry Phenolic Antioxidants-Implications for Human Health? Front. Pharmacol. 2018, 9, 78. [CrossRef]

22. Mazzoni, L.; Perez-Lopez, P.; Giampieri, F.; Alvarez-Suarez, J.M.; Gasparrini, M.; Forbes-Hernandez, T.Y.; Quiles, J.L.; Mezzetti, B.; Battino, M. The genetic aspects of berries: From field to health: The genetic aspects of berries. J. Sci. Food Agric. 2016, 96, 365-371. [CrossRef] [PubMed]

23. Manganaris, G.A.; Goulas, V.; Vicente, A.R.; Terry, L.A. Berry antioxidants: Small fruits providing large benefits. J. Sci. Food Agric. 2013, 94, 825-833. [CrossRef] [PubMed]

24. Pojer, E.; Mattivi, F.; Johnson, D.; Stockley, C.S. The Case for Anthocyanin Consumption to Promote Human Health: A Review. Compr. Rev. Food Sci. Food Saf. 2013, 12, 483-508. [CrossRef] 
25. Essa, M.M.; Al-Adawi, S.; Memon, M.A.; Manivasagam, T.; Akbar, M.; Subash, S. Neuroprotective effects of berry fruits on neurodegenerative diseases. Neural Regen. Res. 2014, 9, 1557-1566. [CrossRef] [PubMed]

26. Castro, D.D.S.B.D.; Teodoro, A.J. Anticancer Properties of Bioactive Compounds of Berry Fruits-A Review. Br. J. Med. Med. Res. 2015, 6, 771-794. [CrossRef]

27. Baby, B.; Antony, P.; Vijayan, R. Antioxidant and anticancer properties of berries. Crit. Rev. Food Sci. Nutr. 2017, 58, 2491-2507. [CrossRef]

28. Brown, E.M.; Gill, C.I.; McDougall, G.J.; Stewart, D. Mechanisms underlying the anti-proliferative effects of berry components in in vitro models of colon cancer. Curr. Pharm. Biotechnol. 2012, 13, 200-209. [CrossRef]

29. Ohene, I.; Maalekuu, B.K. Effect of some postharvest treatments on the quality and shelf life of three cultivars of carrot (Daucus carota L.) during storage at room temperature. Am. J. Clin. Nutr. 2013, 3, 64-72. [CrossRef]

30. Ponder, A.; Hallmann, E. The effects of organic and conventional farm management and harvest time on the polyphenol content in different raspberry cultivars. Food Chem. 2019, 125295. [CrossRef]

31. Gündeşli, M.A.; Korkmaz, N.; Okatan, V. Polyphenol content and antioxidant capacity of berries: A review. Int. J. Agric. For. Life Sci. 2019, 3, 350-361.

32. Paredes-López, O.; Cervantes-Ceja, M.L.; Vigna-Pérez, M.; Hernández-Pérez, T. Berries: Improving Human Health and Healthy Aging, and Promoting Quality Life-A Review. Plant Foods Hum. Nutr. 2010, 65, 299-308. [CrossRef] [PubMed]

33. Greblikaite, J. Development of berry farms in Europe: Organisational and management issues. Mark. Manag. Innov. 2019, 2, 141-159. [CrossRef]

34. Alvarez-Suarez, J.M.; Cuadrado, C.; Redondo, I.B.; Giampieri, F.; González-Paramás, A.M.; Santos-Buelga, C. Novel approaches in anthocyanin research-Plant fortification and bioavailability issues. Trends Food Sci. Technol. 2021. [CrossRef]

35. Veberic, R.; Slatnar, A.; Bizjak, J.; Stampar, F.; Mikulic-Petkovsek, M. Anthocyanin composition of different wild and cultivated berry species. L.W.T. 2015, 60, 509-517. [CrossRef]

36. Määttä-Riihinen, K.R.; Kamal-Eldin, A.; Törrönen, A.R. Identification and Quantification of Phenolic Compounds in Berries ofFragariaandRubusSpecies (Family Rosaceae). J. Agric. Food Chem. 2004, 52, 6178-6187. [CrossRef] [PubMed]

37. Cordeiro, T.; Fernandes, I.; Pinho, O.; Calhau, C.; Mateus, N.; Faria, A. Anthocyanin content in raspberry and elderberry: The impact of cooking and recipe composition. Int. J. Gastron. Food Sci. 2021, 24, 100316. [CrossRef]

38. Bobinaite, R.; Viškelis, P.; Venskutonis, P.R. Variation of total phenolics, anthocyanins, ellagic acid and radical scavenging capacity in various raspberry (Rubus spp.) cultivars. Food Chem. 2012, 132, 1495-1501. [CrossRef]

39. Weber, C.A.; Perkins-Veazie, P.; Moore, P.; Howard, L. Variability of antioxidant content in raspberry germplasm Variability of Antioxidant Content in Raspberry Germplasm. Acta Hortic. 2008, 493-498. [CrossRef]

40. Van de Velde, F.; Grace, M.H.; Esposito, D.; Pirovani, M.É.; Lila, M.A. Quantitative comparison of phytochemical profile, antioxidant, and anti-inflammatory properties of blackberry fruits adapted to Argentina. J. Food Compos. Anal. 2016, 47, 82-91. [CrossRef]

41. Zia-Ul-Haq, M.; Riaz, M.; De Feo, V.; Jaafar, H.Z.E.; Moga, M. Rubus Fruticosus L.: Constituents, Biological Activities and Health Related Uses. Molecules 2014, 19, 10998-11029. [CrossRef]

42. Fan-Chiang, H.; Wrolstad, R.E. C: Food Chemistry and Toxicology Antioxidant and Anti-inflammatory Activities. Science 2005, 70, 93-97.

43. Pantelidis, G.E.; Vasilakakis, M.; Manganaris, G.A.; Diamantidis, G.R. Antioxidant capacity, phenol, anthocyanin and ascorbic acid contents in raspberries, blackberries, red currants, gooseberries and Cornelian cherries. Food Chem. 2007, 102, 777-783. [CrossRef]

44. Jordheim, M.; Enerstvedt, K.H.; Andersen, Ø.M. Identification of Cyanidin 3-O- $\beta$-(6"-(3-Hydroxy-3-methylglutaroyl)glucoside) and Other Anthocyanins from Wild and Cultivated Blackberries. J. Agric. Food Chem. 2011, 59, 7436-7440. [CrossRef]

45. Zdunić, G.; Šavikin, K.; Pljevljakušić, D.; Djordjević, B. Black (Ribes nigrum L.) and Red Currant (Ribes rubrum L.) Cultivars; Elsevier Inc.: Frisco, CO, USA, 2015; ISBN 9780124081178.

46. Borges, G.; Degeneve, A.; Mullen, W.; Crozier, A. Identification of Flavonoid and Phenolic Antioxidants in Black Currants, Blueberries, Raspberries, Red Currants, and Cranberries. J. Agric. Food Chem. 2010, 58, 3901-3909. [CrossRef]

47. Gavrilova, V.; Kajdžanoska, M.; Gjamovski, V.; Stefova, M. Separation, Characterization and Quantification of Phenolic Compounds in Blueberries and Red and Black Currants by HPLC-DAD-ESI-MSn. J. Agric. Food Chem. 2011, 59, 4009-4018. [CrossRef]

48. Wojdyło, A.; Oszmiański, J.; Milczarek, M.; Wietrzyk, J. Phenolic profile, antioxidant and antiproliferative activity of black and red currants (Ribes spp.) from organic and conventional cultivation. Int. J. Food Sci. Technol. 2012, 48, 715-726. [CrossRef]

49. Wu, X.; Gu, L.; Prior, R.L.; McKay, S. Characterization of Anthocyanins and Proanthocyanidins in Some Cultivars of Ribes, Aronia, and Sambucus and Their Antioxidant Capacity. J. Agric. Food Chem. 2004, 52, 7846-7856. [CrossRef]

50. Obón, J.M.; Díaz-García, M.; Castellar, M. Red fruit juice quality and authenticity control by HPLC. J. Food Compos. Anal. 2011, 24, 760-771. [CrossRef]

51. Laczkó-Zöld, E.; Komlósi, A.; Ülkei, T.; Fogarasi, E.; Croitoru, M.; Fülöp, I.; Domokos, E.; Ştefănescu, R.; Varga, E. Extractability of polyphenols from black currant, red currant and gooseberry and their antioxidant activity. Acta Biol. Hung. 2018, 69, 156-169. [CrossRef]

52. Orsavová, J.; Hlaváčová, I.; Mlček, J.; Snopek, L.; Mišurcová, L. Contribution of phenolic compounds, ascorbic acid and vitamin E to antioxidant activity of currant (Ribes L.) and gooseberry (Ribes uva-crispa L.) fruits. Food Chem. 2019, 284, 323-333. [CrossRef] 
53. Benvenuti, S.; Pellati, F.; Melegari, M.; Bertelli, D. Polyphenols, Anthocyanins, Ascorbic Acid, and Radical Scavenging Activity of Rubus, Ribes, and Aronia. J. Food Sci. 2006, 69, FCT164-FCT169. [CrossRef]

54. Brambilla, A.; Scalzo, R.L.; Bertolo, G.; Torreggiani, D. Steam-Blanched Highbush Blueberry (Vaccinium corymbosum L.) Juice: Phenolic Profile and Antioxidant Capacity in Relation to Cultivar Selection. J. Agric. Food Chem. 2008, 56, 2643-2648. [CrossRef] [PubMed]

55. Scalzo, J.; Stevenson, D.; Hedderley, D. Blueberry estimated harvest from seven new cultivars: Fruit and anthocyanins. Food Chem. 2013, 139, 44-50. [CrossRef] [PubMed]

56. Giovanelli, G.; Buratti, S. Comparison of polyphenolic composition and antioxidant activity of wild Italian blueberries and some cultivated varieties. Food Chem. 2009, 112, 903-908. [CrossRef]

57. Skrovankova, S.; Sumczynski, D.; Mlcek, J.; Jurikova, T.; Sochor, J. Bioactive Compounds and Antioxidant Activity in Different Types of Berries. Int. J. Mol. Sci. 2015, 16, 24673-24706. [CrossRef] [PubMed]

58. Stevenson, D.; Scalzo, J. Anthocyanin composition and content of blueberries from around the world. J. Berry Res. 2012, 2, 179-189. [CrossRef]

59. Wu, X.; Beecher, G.R.; Holden, J.M.; Haytowitz, D.B.; Gebhardt, A.S.E.; Prior, R.L. Concentrations of Anthocyanins in Common Foods in the United States and Estimation of Normal Consumption. J. Agric. Food Chem. 2006, 54, 4069-4075. [CrossRef] 